\title{
DEMOCRACIA, MILITARES Y POLÍTICA EXTERIOR EN MÉXICO: EL CASO DE LA AUSENCIA DE MÉXICO CON EFECTIVOS MILITARES EN OPERACIONES DE MANTENIMIENTO DE LA PAZ DE LA ONU
}

Raúl ZePeda GiL ${ }^{1}$

El 24 de SePtiembre de 2014, el presidente Enrique Peña Nieto anunció la incorporación gradual de México en las Operaciones de Mantenimiento de la Paz (omp) de la Organización de las Naciones Unidas (ONU) con efectivos militares en el marco del debate general del $69^{\circ}$ periodo de sesiones de la Asamblea General de la Organización. Esta decisión era probable a partir de que la Secretaría de la Defensa Nacional (Sedena) publicara en 2013 su nuevo Programa Sectorial para el periodo 2013-2018. En este programa la Secretaría marca como objetivo 1.7.8.: "Asistir a actividades internacionales relacionadas con las operaciones de paz, para estudiar la posible participación en este tipo de operaciones". Este objetivo es nuevo a comparación del Programa Sectorial de la misma Secretaría para el sexenio 2007-2012, que sólo menciona en la línea de acción 3.6.3.: "Atender invitaciones de organismos internacionales de índole político-militar, para fortalecer a México en el exterior, con apego a los principios establecidos en la materia". ${ }^{2}$ Es también importante mencionar que en los programas sectoriales de la

${ }^{1} \mathrm{El}$ autor agradece los comentarios y sugerencias de Mónica Serrano para la realización de este documento. Además agradece a la profesora Martha Elena Venier por su apoyo en la corrección de estilo del texto. En todo caso, los errores, opiniones y malentendidos corren a cuenta del autor.

${ }^{2}$ Secretaría de la Defensa Nacional, Programa Sectorial de Defensa Nacional: 
Secretaría de Marina (Semar) no se menciona el asunto. El nuevo objetivo representa un cambio gradual de la Sedena sobre su posición con respecto a participar en OMP de la ONU. Las Fuerzas Armadas Mexicanas -la Sedena y la Semar- se han opuesto de manera consistente a participar en las omp desde la administración de Carlos Salinas de Gortari, aunque, como veremos, la reticencia sería menor por parte de la Semar. La presión a México para participar en las OMP ha venido desde la misma onU, otros países que participan en las OMP, ${ }^{3}$ la burocracia -renovada desde los años setentade la Secretaría de Relaciones Exteriores (SRE) y, desde el sexenio de Vicente Fox, de sus funcionarios y legisladores del Partido Acción Nacional (PAN).

¿Por qué México no enviaba efectivos militares, aunque participaba con otro tipo de personal, a las OMP? Y ¿por qué el presidente Enrique Peña Nieto decidió que México enviaría efectivos? En primer término afirmo que las doctrinas de política exterior y de defensa nacional evitaron que México participara en las operaciones de paz con efectivos militares. Además, el cambio gradual de las opiniones de la burocracia de la SRE, ex secretarios de Estado como Bernardo Sepúlveda, ${ }^{4}$ una reiterada petición de gobiernos de otros países a México de participar en estas misiones, la llegada de los gobiernos, y de senadores, del PAN, promotores de la agenda multilateral, crearon una coalición, aunque no sólida en ocasiones, que dirigió sus estrategias alrededor de convencer al sector militar de pronunciarse a favor de participar dichas operaciones. Esta

2013-2018, México, 2013, p. 34; y Secretaría de la Defensa Nacional, Programa Sectorial de Defensa Nacional: 2007-2012, México, 2007, p. 27.

${ }^{3}$ Esta información proviene de las entrevistas realizadas para este artículo. Al ser información que proviene de diálogos informales en el seno de la onU, los países no publicitan sus opiniones sobre México. En el caso de las Operaciones en las entrevistas, se mencionó los países de América Latina que participan constantemente en las mismas, aunque no se precisó cuáles países. En la siguiente sección expongo de manera más amplia la petición pública del entonces presidente de Francia, Nicolás Sarkozy.

${ }^{4}$ Bernardo Sepúlveda, "Una asignatura pendiente: la participación de México en las operaciones de paz de la onU", en Miguel Covián (ed.), Cumbre del Milenio: ¿Hacia dónde van las Naciones Unidas?, México, Instituto Matías Romero, Secretaría de Relaciones Exteriores, 2001. 
coalición logró convencer de manera gradual al sector militar, pero las condiciones de opinión pública alrededor del tema del narcotráfico en México evitaron que los gobiernos del PAN anunciaran esta medida. Las condiciones de diálogo intergubernamental iniciadas en las administraciones del pan, el activismo del embajador Juan Manuel Gómez Robledo y un ambiente de opinión pública más favorable permitieron a la administración del PRI decidir que México debería participar con efectivos militares en estos esfuerzos multilaterales.

Para explicar este cambio gradual y la estrategia conjunta de convencimiento, hago una narración de este proceso e incorporo las perspectivas teóricas de toma de decisiones burocrático-organizacionales de Allison ${ }^{5}$ y el modelo incremental de cambio en política pública de Lindblom; considero esta decisión tanto para la política exterior mexicana cuanto para las relaciones cívico militares en México. ${ }^{6}$ Como explicaré más adelante, para matizar la idea de coalición de actores que sostengo, la Secretaría de Relaciones Exteriores fue el actor principal que convenció al sector militar de participar en las омР, para con ello facilitar al presidente de la República el despliegue de militares. A pesar de que el Senado participó en el proceso, fue el diálogo entre sRE-Sedena y Semar el cual, de manera gradual, cambió la posición de las últimas secretarías, con lo cual mejoraría la posición del presidente de la República para determinar la participación de México en las mencionadas misiones. El artículo se divide en cuatro secciones: la primera trata de la formación de las doctrinas militares y de política exterior durante los gobiernos post-revolucionarios; la segunda examina los inicios del cambio de objetivos de política exterior y su conflicto con el mantenimiento del pacto civil-militar; la tercera analiza las condiciones de la toma de la decisión del presidente y los actores involucrados. La cuarta, y última, destaca las implicaciones teóricas y de política pública de esta decisión.

${ }^{5}$ Graham T. Allison, "Conceptual Models and the Cuban Missile Crisis", American Political Science Review, vol. 63, núm. 3, 1969, pp. 689-718.

${ }^{6}$ Charles E. Lindblom, "Still Mudding not yet Through", Public Administration Review, vol. 39, 1979, pp. 317-339. 
DOCTRINAS GONCORDANTES: ENTRE EL PACTO CÍVICO MILITAR Y LA POLÍTICA EXTERIOR DEL NO

Las Fuerzas Armadas y el poder civil han mantenido un pacto tácito de respeto y autonomía sobre sus respectivas esferas de decisión a partir de la profesionalización, la despolitización y la necesidad de una política exterior que mantuviese la independencia de Estados Unidos. ${ }^{7}$ La profesionalización y la concordancia de principios políticos sobre la relación con el exterior son formas reconocidas de control civil sobre el sector militar. ${ }^{8}$ Hay varias teorías que compiten con la teoría tradicional del control civil en las relaciones de civiles con militares. La teoría de la concordancia expone que los sectores civil y militar mantienen relaciones fluidas por medio de creencias y objetivos comunes que dan razón a la jerarquía civil por sobre la militar. ${ }^{9}$ Además, la teoría de responsabilidad conjunta expone que ambos sectores comparten tareas y, por lo tanto, las responsabilidades ante la población. ${ }^{10}$ Más allá de la validez de las teorías, deseo explicar que se pueden ver -como se argumenta abajo- momentos en que la política exterior pasa por fases parecidas a cualquiera de estas teorías.

Las relaciones entre el sector civil y el militar en México transitaron por diversos mecanismos objetivos y subjetivos de concordancia: en primer lugar, por un especial acento nacionalista pues se otorga al Ejército el papel de "guardianes de la revolución”. En segundo lugar, han pasado por la reducción de la influencia de los militares en puestos de poder político. La influencia militar, fuera de la Sedena, ha sido la elección de algunos militares retirados para que como diputados o senadores ocuparan asientos en las

${ }^{7}$ Mónica Serrano, "The Armed Branch of the State: Civil-Military Relations in Mexico”, Journal of Latin American Studies, vol. 27, núm. 2, 1995, pp. 423-448; y Roderic Ai Camp, Las fuerzas armadas en el México democrático, México, Siglo XXI, 2010.

${ }^{8}$ Samuel P. Huntington, The Soldier and the State: The Theory and Politics of CivilMilitary Relations, Nueva York, Vintage Books, 1964, pp. 80-97.

${ }^{9}$ Rebeca L. Schiff, "Civil-Military Relations Reconsidered: A Theory of Concordance”, Armed Forces Ẽ Society, vol. 22, núm. 7, 1995, pp. 7-24.

${ }^{10}$ Douglas L. Bland, "A Unified Theory Of Civil-Military Relations", Armed Forces EV Society, vol. 26, núm. 7, 1999, pp. 7-26. 
comisiones de defensa nacional y de marina; esta práctica sigue vigente. ${ }^{11}$ Debe mencionarse que las embajadas de México tienen agregados militares designados por el presidente. Además, algunos diplomáticos también tuvieron antecedentes militares, como el general Ramón Rafael Macedo Figueroa, quien fue embajador de México ante Panamá en el sexenio de Luis Echeverría. En tercer lugar, y probablemente el más importante de la relación entre poder civil y político, hubo una falta casi absoluta de involucramiento civil en las secretarías de la Defensa y de la Marina. El actor que cuenta con una relación exclusiva con las fuerzas armadas es el presidente; ${ }^{12}$ por ello, él ha tomado decisiones en los temas que involucran a los militares y al sector diplomático. Me refiero en específico a las decisiones del presidente Miguel Alemán con respecto a las primeras misiones de paz de la onU después de la fundación de la organización, y, también, a la determinación de Gustavo Díaz Ordaz de que México no se incorporara a la Misión Interamericana de Paz que creó la Organización de Estados Americanos en 1965 y que sin embargo desapareció en 1971. Debe mencionarse que, desde el sexenio de Carlos Salinas, se aceptó a civiles, entre ellos diplomáticos, en los cursos del Colegio de la Defensa Nacional y del Centro de Estudios Navales, de la Sedena y la Semar respectivamente.

El ejército ha mantenido, como uno de sus principios más importantes de participación en el exterior, la no intervención. ${ }^{13}$ A pesar de esporádicas presencias de las Fuerzas Armadas en mantenimiento de la paz (la última fue con la Misión de Observación Militar en la India y Pakistán en 1949), México no ha participado con efectivos militares en operaciones fuera del territorio nacional con fines de paz, exclusivamente en operaciones de

11 Javier Ibarrola, El Ejército y el poder: impacto e influencia política en el México moderno, México, Océano, 2003, p. 327.

12 Jordi Díez, "Legislative Oversight for the Armed Forces in Mexico", Mexican Studies, vol. 24, núm. 1, 2008, pp. 113-145.

${ }^{13}$ Jesús E. Encinas Valenzuela, "To Do or Not to Do: Mexican Foreign Policy and UN Peacekeeping Operations in the 21st Century", tesis de Maestría en Ciencia en Análisis de Defensa, Naval Postgraduate School, Monterey, California, 2006, p. 49. 
fines humanitarios en desastres naturales, aunque sí ha habido una amplia participación de México en otras operaciones de paz, onUSAL en específico, con personal civil y cuerpos de policía. En una de las ocasiones que se discutió la presencia de tropas en una misión de la onu, Santiago Roel, secretario de Relaciones Exteriores, planteó al presidente López Portillo participar en la Fuerza Interina en Líbano, pero este diálogo se detuvo cuando Jorge Castañeda y Álvarez de la Rosa sustituyó al secretario Roel. A pesar de las solicitudes de otros países para que México participara, sobre todo en la región de América Latina, las Fuerzas Armadas han considerado que las operaciones de paz pueden entenderse como actos de intervención en otros países. Caso ejemplar fue el cuestionamiento a México por no participar en la Misión de Estabilización de las Naciones Unidas en Haití, en el cual, a pesar de haber enviado policías a El Salvador, se invocaron los principios constitucionales de política exterior. ${ }^{14}$ En un caso pocas veces visto, Nicolás Sarkozy, entonces presidente de Francia, dijo ante el Senado el 11 de marzo de 2009:

Sé que el tema de la participación de México en las operaciones de mantenimiento de la paz es objeto de debate en su país. Respeto este debate y sé que este debate reviste una sensibilidad particular. Las decisiones de México, que provienen de su historia, son decisiones naturalmente soberanas. Pero los aliento, como amigo, a proseguir la valiente reflexión que han emprendido al respecto. El mundo necesita de México y la contribución que puede aportar puede revestir diferentes formas. Quien les está hablando es alguien que aboga por un lugar permanente de México en la gobernanza mundial. Francia tiene ese lugar, pero ese lugar, Queridos Amigos Mexicanos, se caracteriza por tener derechos, y también obligaciones. $^{15}$

${ }^{14}$ Raúl Benítez, “América Latina: Operaciones de Paz y Acciones Militares Internacionales de las Fuerzas Armadas", Foro Internacional, vol. 47, núm. 1, 2007, p. 110.

${ }^{15}$ Senado de la República, Diario de los Debates, 11 de marzo de 2009, Segundo Periodo Ordinario, LX Legislatura, Diario 13. 
Interesante es que Francia, como miembro permanente del Consejo de Seguridad de la onu, considere que México, de manera velada, no cumplía con sus responsabilidades internacionales.

De manera paralela y con la confluencia de los principios de política exterior plasmados en la Constitución, la diplomacia mexicana enfrentó un reto constante: la relación con Estados Unidos que ha sido la limitación más importante a la política exterior mexicana y además el riesgo de que, en el ámbito multilateral, se podría tensar la relación entre los dos países. ${ }^{16}$ En este ámbito la tendencia a evadir el conflicto con Estados Unidos se expresó en la ausencia constante de México en el Consejo de Seguridad de la ONU. ${ }^{17}$ Esta ausencia, tanto en el Consejo de Seguridad de la ONU como en las omp, se debe al poco interés de México en asuntos de países lejanos al interés nacional; ${ }^{18}$ además, la participación de México en el Consejo de Seguridad se vería como una responsabilidad sin beneficios tangibles. ${ }^{19}$ Los límites de la política exterior mexicana, y fijados en el principio de no intervención, se expresarían en el ámbito multilateral como la abstención de México en la Doctrina Tello. Para Manuel Tello, la política exterior mexicana debía cifrarse, en la medida de lo posible, en intereses que México tuviese en el exterior; por ello, participar en el Consejo de Seguridad hubiese sido poco útil, además de que, en temas humanitarios, se podría justificar la intervención de países desarrollados en países subdesarrollados; por lo demás, añadía que participar en estos foros, mecanismos e iniciativas podría, ante la asimetría de

${ }^{16}$ Esto puede ser revisado en Sepúlveda Amor, Bernardo, "México, el Consejo de Seguridad y el futuro de la onU”, Foro Internacional, núm. 142, 1995, pp. 461475, Mario Ojeda, Alcances y límites de la política exterior de México, México, El Colegio de México, 1976.

${ }^{17}$ Juan Manuel Gómez Robledo, "El Consejo de Seguridad en la política exterior mexicana”, en Roberto Dondisch, México en el Consejo de Seguridad de la ONU: La historia tras bambalinas, México, SRE/Random House Mondadori/Debate, 2012, p. 17.

18 Fernando González Saiffe, "México ante las operaciones de mantenimiento de la paz en el Consejo de Seguridad 2009-2010", pp. 165-197.

19 Arturo C. Sotomayor, "México y la onU en tiempos de transición: Entre activismo externo, parálisis interna y crisis internacional”, Foro Internacional, vol. 48, núm. 1, 2008, pp. 238-267. 
poder con Estados Unidos, resultar más problemático, conque, de nuevo, no habría beneficios concretos. ${ }^{20}$

Por razones históricas la doctrina de política exterior mexicana y la doctrina de relaciones civiles y militares en México se expresaron por medio de los principios de no intervención y de defensa de la soberanía nacional. Ambas doctrinas se expresan en la concordancia de objetivos entre los sectores diplomático y militar durante la mayor parte del siglo xx. El control civil más claro sobre el sector militar ha sido el presidente de la República, y mientras el sector diplomático no solicitara mayor participación de México en el ámbito de las OMP, no habría cambio con respecto al sector militar. Está situación cambió con el apoyo explícito de los entonces secretarios de relaciones exteriores, Bernardo Sepúlveda y Rosario Green, lo cual mostraría un cambio gradual de las perspectivas de la cancillería y de su liderazgo.

\section{ASPIRANDO A SER POTENCIA: LAS TENSIONES ENTRE MILITARES Y DIPLOMÁTICOS}

La política exterior de México ha cambiado de manera constante a partir de los procesos de apertura comercial, de participación más activa en foros multilaterales y de la alternancia democrática. La pertenencia de México a nuevos mecanismos multilaterales, como la omc o la ocDE, ha permitido al país proyectarse como una potencia media en política exterior multilateral. En específico, en la onu, México participó activamente en temas que no le eran cercanos en años anteriores; por ejemplo, su intervención en el proceso de paz de El Salvador en 1992 llevó a ser un contribuyente relevante en la Misión de Observación de las Naciones Unidas en ese país con personal policial, a pesar de la presencia de México en la región, pero no en los mecanismos de mantenimiento de la paz de la onu. Desde ese entonces, hasta el sexenio de Vicente

${ }^{20}$ Se pueden revisar con detalle las declaraciones de Manuel Tello en Ana Covarrubias y Laura Muñoz (eds.), Manuel Tello: por sobre todas las cosas México, México, SRE-IMr, 2007. (Historia Oral de la Diplomacia Mexicana, 3.) 
Fox, y todavía en la administración de Felipe Calderón, la participación de México ha sido más activa en el Consejo de Seguridad de la ONU y en las discusiones sobre paz y seguridad internacionales. La transición a la democracia y el cambio de partido provocaron una actualización, proveniente de años anteriores, de las actitudes y activismo de México en el ámbito multilateral..$^{21}$ Pero la ausencia de México con efectivos militares en Operaciones de Paz de la ONU ha limitado los alcances de la nueva política exterior activa en asuntos multilaterales. ${ }^{22} \mathrm{El}$ resultado en términos de política exterior de esta ausencia con activos militares se ha interpretado como que México ha seguido una doctrina nacionalista y segregacionista en el tema. ${ }^{23}$ A pesar de todo, los tiempos de la Doctrina Tello parecen haber cedido lugar a los de una política exterior más comprometida con la agenda de paz y seguridad internacionales, sobre todo en la agenda de derechos humanos. Cabe señalar que claramente México ha tenido una intensa política exterior multilateral en otros ámbitos, por ejemplo, en la agenda de cambio climático y del desarme nuclear. Otro ejemplo claro de la disminución de la importancia de la Doctrina Tello fue la incorporación en 1988 de la defensa de la paz y seguridad internacionales como parte de la doctrina constitucional de política exterior. ${ }^{24}$

A pesar de los cambios políticos en diversas arenas de política en México por la transición a la democracia, el sector militar fue uno de los pocos que no sufrieron cambios sustanciales de ningún tipo. ${ }^{25}$ La autonomía del sector militar se reafirmó y los mecanismos que se usaron durante los gobiernos del PRI se mantuvieron

${ }^{21}$ Sotomayor, op. cit.

22 Olga Pellicer, "México como potencia media en la política multilateral, 2006-2012”, Foro Internacional, vol. 53, núm. 3, 2013, pp. 873-896.

${ }^{23}$ Arturo C. Sotomayor, "Why Some States Participate in UN Peace Missions While Others Do Not: An Analysis of Civil-Military Relations and Its Effects on Latin America's Contributions to Peacekeeping Operations", Security Studies, vol. 19, núm. 1, 2010, pp. 160-195.

${ }^{24}$ Artículo 89, fracción X de la Constitución Política de los Estados Unidos Mexicanos. Reforma publicada en el Diario Oficial de la Federación el 11 de mayo de 1988.

${ }^{25}$ Ai Camp, op. cit. 
durante los sexenios del PAN. En esas condiciones la burocracia de la Secretaría de Relaciones Exteriores inició un proceso de diálogo político sobre la posibilidad de que México participara en Operaciones de Paz con efectivos militares. El establecimiento de una Operación Multidimensional en Haití fue motivación persistente para México en el campo internacional. En estas condiciones, la burocracia de la SRE insistió en la participación de la Sedena y la Semar en las omp. En repetidas ocasiones la Semar se ha mostrado más dispuesta a participar que la Sedena. ${ }^{26}$ En cualquiera de los casos, ambas secretarías han mantenido la posición de que México no puede participar legalmente en las misiones y de que sería una violación de la doctrina de no intervención. ${ }^{27}$ Más allá de que los análisis jurídicos puedan discrepar del diagnóstico de ambas secretarías, ${ }^{28}$ el conflicto entre sector diplomático y sector militar está más relacionado con la jerarquía presidencial.

El episodio más evidente de conflicto entre diplomáticos y militares fueron las discrepancias públicas entre la SRE y la Sedena en 2005, cuando la subsecretaria para asuntos multilaterales, Patricia Olamendi, fue enmendada en sus opiniones favorables a la participación de México en las omp por el vocero de la presidencia por presión de la Sedena. ${ }^{29}$ Abajo explico más a fondo las implicaciones de estos episodios en la decisión pública, pero resulta claro que, mientras que la transición democrática afectó la política exterior en México, confluyendo con el cambio de opinión de su burocracia, el mismo fenómeno no influyó de manera ostensible en la

${ }^{26}$ En las entrevistas hay versiones diferentes sobre la intención de la Semar de participar, pero dos de ellas indican que la Semar está más dispuesta a participar en omp. En la Revista de la Centro de Estudio Navales de la Semar se discutió por varios miembros de esta secretaría sobre la participación en la Marina en las OMP en los números 2007-2, 2009-1 y 2012-1. Una visión favorable sería la del vicealmirante Luis Gerardo Alcalá Ferráes en un artículo de la revista titulado "Operaciones de Mantenimiento de la Paz” del número 2012-2, abril-junio, de las páginas 23 a la 36.

27 Carlos Rodríguez Ulloa, "México ante el multilateralismo del siglo xxI. Entre los principios de política exterior y las Operaciones de Mantenimiento de la Paz", Revista de Relaciones Internacionales de la UNAM, 105, 2009, pp. 109-133.

${ }^{28}$ Gonzalez Saiffe, op. cit.

${ }^{29}$ Este episodio puede revisarse en Sotomayor, 2008, op. cit. 
relación civil militar. La responsabilidad conjunta no fue suficiente para disuadir a las Fuerzas Armadas.

\section{EL LABERINTO DE LA DECISIÓN PRESIDENCIAL}

El esquema de burocracias en competencia de Allison ayuda a comprender la tensión entre los actores de la decisión. Allison sostiene que hay tres modelos de tomas de decisiones: racional, burocrático y organizacional. Las decisiones en cada esquema responden a diferentes insumos. El primer insumo es un análisis costo-beneficio sobre la decisión que se tomará. El segundo es la inercia procedimental con la cual las burocracias orientan la toma de decisiones, es decir, que tienen un protocolo o una forma particular de responder a ciertos problemas. El tercero es la presión de las organizaciones involucradas para que se tome cierta decisión. El autor sostiene que las decisiones se toman en una conjunción de estos tres tipos de insumos. Como explicaré abajo, el insumo racional es el ambiente de opinión pública sobre el tema de fuerzas armadas y seguridad. El insumo burocrático son las doctrinas de política exterior y de defensa, que, como hemos revisado, han cambiado a lo largo de los años. El insumo organizacional son las presiones que han insertado la SRE, la Sedena y la Semar en las consideraciones del presidente de la República. Además, la aproximación gradual a los cambios de política pública de Lindblom explica, en buena medida, cómo las doctrinas y las posiciones organizacionales cambian en el tiempo. Faltaba para la toma de la decisión que hubiese un clima de opinión pública favorable para que fuera racional enviar efectivos militares a las OMP.

La SRE ha enfocado sus esfuerzos en convencer a las burocracias de la Sedena y la Semar para aceptar la participación en OMP. De manera paralela, la SRE trató de convencer, sin éxito, al presidente, en varias ocasiones, desde el sexenio de Carlos Salinas. ${ }^{30}$ Los

${ }^{30}$ En las entrevistas se señalaron las diversas rondas de negociación entre los secretarios con el presidente Fox y Calderón, y que miembros del servicio exterior le expresaban que esos mismos intentos se habían dado con Salinas y Zedillo. 
hechos indican que no sólo se trata de obtener el consenso de las burocracias en competencia; también es necesario que las condiciones de opinión pública permitan al presidente tomar dicha determinación. En diversos estudios se ha confirmado, para Estados Unidos, que el presidente necesitaba un ambiente favorable de opinión pública y presión internacional para enviar tropas fuera de su territorio. ${ }^{31}$

Dos eventos disuadieron en su momento al presidente de tomar la decisión de enviar a las Fuerzas Armadas a OMP. La primera fue la presión inicial de la Sedena, que contaba con una opinión pública favorable de manera constante en las encuestas sobre instituciones: México es el país con más aceptación de las Fuerzas Armadas de América Latina según Latinobarómetro. La aceptación de las Fuerzas Armadas en México supera, desde 2005, más de $50 \%$ (véase la gráfica 1). De igual manera, en la población general hay confianza por la participación de México con efectivos militares en las OMP de la onu (véase la gráfica 2). Debe destacarse que las Fuerzas Armadas son la institución nacional más apreciada en México según Latinobarómetro. Aunque las Fuerzas Armadas forman parte del gobierno, en la encuesta se pregunta por separado a gobierno y Fuerzas Armadas, y el gobierno tiene menos de $40 \%$ de apoyo. En la encuesta no se pregunta por secretarías, pero puede deducirse que el encuestado vería a la Secretaría de Relaciones Exteriores como el gobierno, vis á vis las Fuerzas Armadas como una institución separada.

En 2005, Vicente Fox decidió no enviar efectivos por la opinión favorable que gozaban a las Fuerzas Armadas -los años más altos en la historia de la institución- a pesar de la opinión popular favorable. El segundo evento fue la llamada política de seguridad intensiva de Felipe Calderón contra las organizaciones criminales dedicadas al

${ }^{31}$ Entre otros se puede revisar Bradley Lian y John R. Oneal, "Presidents, the Use of Force, and Public Opinion", Journal of Conflict Resolution, vol. 37, núm. 2, 1993, pp. 277-300; James Meernik, "Presidential Decision Making and the Political Use of Force", International Studies Quaterly, 38, 1994, pp. 121-138; y Patrick James y John R. Oneal, "The Influence of Domestic and International Politics of the President's Use of Force”, Journal of Conflict Resolution, vol. 35, núm. 2, 1991, pp. 307-332. 
tráfico de drogas. Las valoraciones de la presidencia indicaban que se debía evitar una salida de tropas en un contexto poco favorable al uso de militares en tareas no relacionadas con seguridad bajo el argumento de que podría percibirse como una distracción.

\section{GRÁFICA 1}

Opinión favorable de la población sobre las Fuerzas Armadas en México

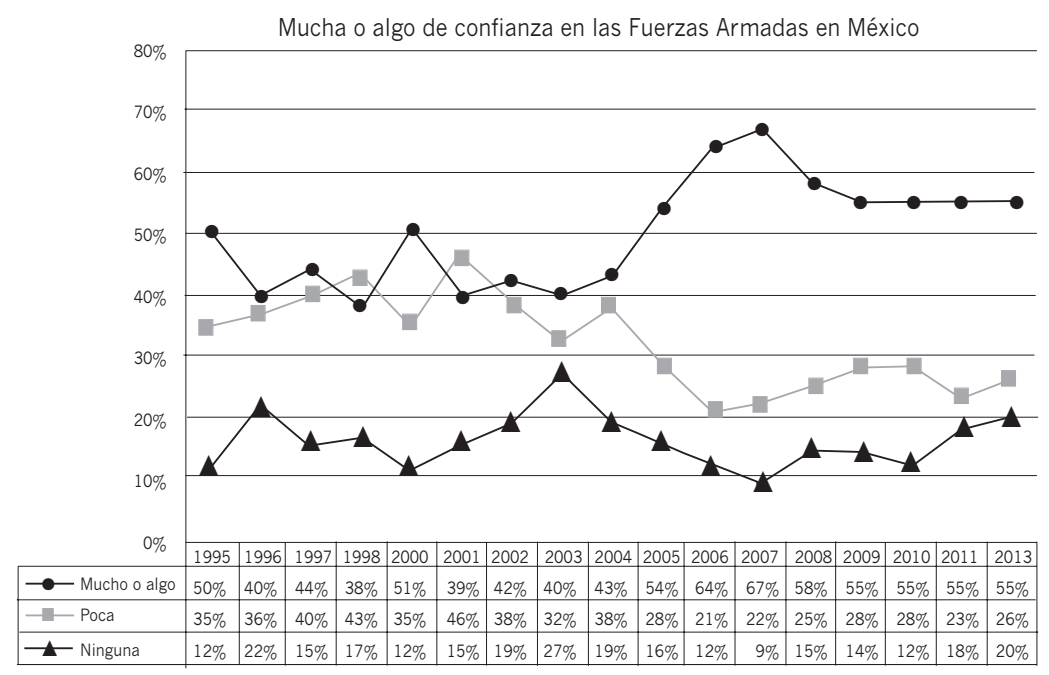

Fuente: Latinobarómetro, series de tiempo para México.

La decisión del presidente de la República de enviar tropas a las OMP de la ONU debe pasar por autorización del Senado. En los dos sexenios pasados, ningún partido tuvo la mayoría del Senado para evitar el veto de cualquier otro grupo parlamentario; necesariamente se debía conseguir una coalición entre el PAN y el PRI para lograrlo. En ambos sexenios, el PRI no se posicionó públicamente en ningún sentido. El PAN ha mantenido una posición a favor de manera constante. Las senadoras Adriana González, Laura Rojas y Gabriela Cuevas han presentado iniciativas para modificar la Constitución y hacer más clara la participación de México en 
las OMP. En el PRD la opinión ha sido en contra de una eventual salida. El senador Antonio Soto Sánchez (PRD) presentó una iniciativa para aumentar el control del Senado sobre la salida de tropas y sólo permitir sin autorización una salida por asuntos humanitarios. Las iniciativas en el Senado han tenido la finalidad de permitirle a ese órgano tener mayor participación en el tema y ofrecer mayor seguridad jurídica a la Sedena y la Semar.

\section{GRÁFICA 2}

Opinión sobre la participación de México con efectivos militares en Operaciones de Paz de la ONU

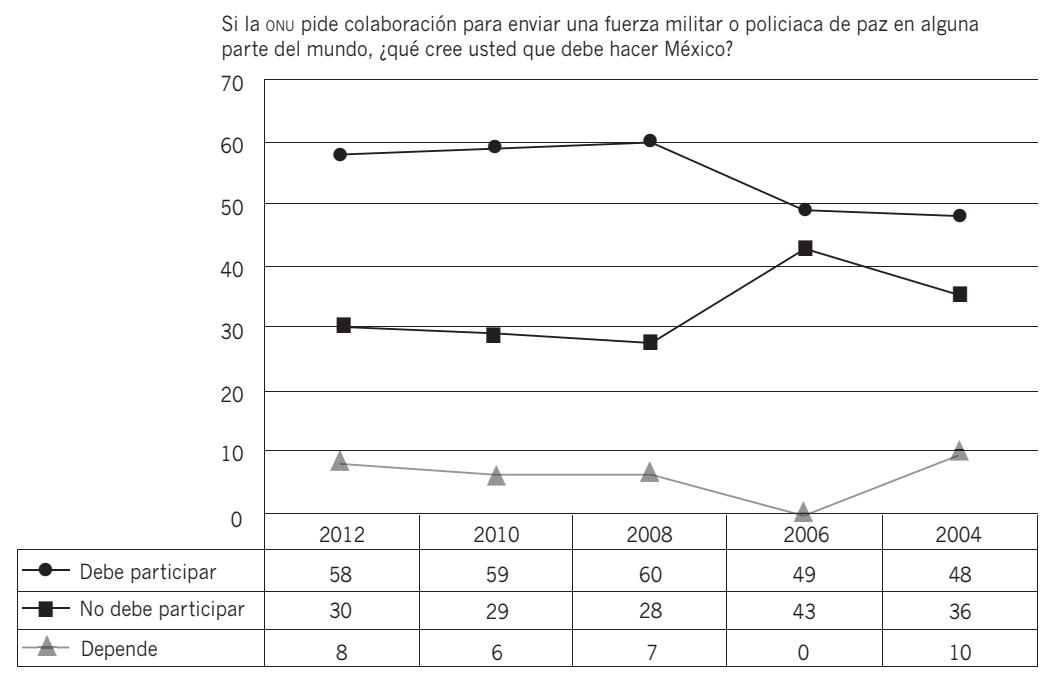

Fuente: Encuesta Cide, "México, las Américas y el Mundo 20012-2013, Política exterior: Opinión Pública y Líderes”, tablas descriptivas.

El Programa Sectorial de la Sedena fue el primer paso sustancial que permitió al presidente tomar la decisión de enviar tropas. Peña Nieto tuvo mejores condiciones para un envío de tropas, porque obtendría el apoyo del grupo parlamentario de su partido y del PAN. Los esfuerzos de diálogo constante de la SRE con las fuerzas armadas dieron resultado. Todos los actores se centraron en el 
convencimiento del presidente como único actor legitimado legalmente para controlar y cambiar las decisiones de las Fuerzas Armadas. El favorable ambiente interno, junto con la relación casi única entre presidente y fuerzas armadas, mejoró las prospectivas para una salida de tropas. Pero, si las crisis de derechos humanos en Tlatlaya e Iguala hubiesen sucedido antes de la sesión de la Asamblea General en la que Peña Nieto anunció la incorporación de México en las omp con efectivos militares, probablemente hubiese sido más complicado para el gobierno tomar esa misma decisión en un ambiente de opinión pública adverso en el tema de seguridad por el involucramiento de militares en Tlatlaya y por la acusación de medios de comunicación contra las Fuerzas Armadas en Iguala. $^{32}$

\section{LOS MULTILATERALISTAS SE ENCUENTRAN}

He expuesto, en gran medida, el cambio gradual de las opiniones de los diferentes actores involucrados en la decisión de enviar tropas a las OMP. Sus opiniones cambian porque hay nuevas generaciones que ocupan las burocracias y puestos de decisión. Por ello, los esquemas de Allison y Lindblom se acoplan en un mismo relato de cómo una decisión de este tipo, que involucra más de una burocracia, requiere de cambios doctrinales y diálogo permanente. Allison sostiene que el escenario internacional plantea los cursos de acción, pero las burocracias tendrán el papel de convencer a los funcionarios de elegir uno de esos cursos de acción. En la época de la doctrina Tello, abiertamente opuesta a mandar tropas a las OMP, y en una época en la que igualmente las Fuerzas Armadas mantenían inmutable su opinión sobre la participación en el exterior, era imposible, por más que las situaciones de Líbano y El Salvador fueran importantes en términos internacionales, que el presidente hubiese dispuesto de tropas. Pequeñas decisiones graduales abrieron el camino para la decisión de Peña Nieto, no

${ }^{32}$ Christopher Hill, The Changing Politics of Foreign Policy, Nueva York, Palgrave, 2003, pp. 224-229. 
sólo los diálogos a puerta cerrada de las secretarías de Relaciones Exteriores, Marina y Defensa, también la inclusión de civiles en los centros de pensamiento militar, el Colegio de la Defensa Nacional y el Centro de Estudios Navales, el envío de policía en la onusal, los cambios constitucionales en materia de política exterior, que involucraban la paz y la seguridad internacionales (que se habían dado durante la administración de Miguel de la Madrid), y la participación de México en el Consejo de Seguridad de la onu en dos bienios, que por lo demás también contó con agregados militares y navales. Lindblom sostiene que la política pública -y en este caso sí se considera a la política exterior como política pública-, no suele cambiar de manera radical, sino que es un proceso de construcción gradual, de pequeños avances en una dirección. Claramente puede haber retrocesos significativos en procesos de este tipo; por ejemplo, ¿el presidente Fox hubiese decidido que México enviara tropas a laminustaH si la subsecretaria Olamendi no hubiese hablado abiertamente del proceso de diálogo en puerta cerrada con la Sedena y la Semar? Quizás sí. Es por ello necesario insistir en que la Secretaría de Relaciones Exteriores, que, en más de una ocasión, lidia con otras burocracias, avanza en el ámbito multilateral en la medida que los actores internos se lo permitan y, también, en que sus propias doctrinas y esos actores lo crean conveniente. Por eso, aunque el escenario internacional haga imperativa la toma de una decisión, por ejemplo, países demandantes, crisis internacionales, críticas sobre responsabilidad (no puede ser casual que el eje de política exterior del presidente Peña Nieto se llame "México con responsabilidad global”), probablemente pesarán más los actores domésticos en este escenario.

Es prudente reconocer también el papel de la opinión pública en este tipo de decisiones. El presidente Felipe Calderón no actuó porque en la agenda de seguridad pública tenía el tema del fuero militar. Ante las violaciones de derechos humanos de la Sedena y, en menor proporción de la Semar, en operativos conjuntos contra organizaciones criminales, el presidente enfrentaba las demandas de seguridad jurídica de ambas secretarías para participar en seguridad pública; al mismo tiempo recibía la crítica del Consejo de Derechos Humanos de la onu por la amplitud del fuero 
militar. Calderón decidió apoyar la demanda de Sedena y Semar con la Ley de Seguridad Nacional, que no prosperó, y correspondió a la Suprema Corte de Justicia de la Nación limitar el fuero militar en caso de que civiles fueran víctimas de exceso del uso de la fuerza por parte de efectivos militares. Peña Nieto en cambio tuvo un ambiente de opinión pública más favorable en los primeros dos años de su administración: los temas de seguridad pasaron al segundo plano de las noticias nacionales e internacionales, a diferencia del sexenio pasado, y el retiro de objeciones de México a muchos tratados internacionales de derechos humanos causó mejor impresión en organismos internacionales. La Sedena publicitó discretamente su intención de participar en OMP. El anuncio de Peña Nieto durante su discurso ante la Asamblea General culminó un proceso que coincidía con el énfasis en responsabilidades globales de su plataforma de política exterior. Si las ejecuciones extrajudiciales en Tlatlaya o la acusación de los padres de los estudiantes desaparecidos en Ayotzinapa hubiesen sido antes del debate de la Asamblea General, ¿el presidente hubiese podido anunciar lo mismo que hizo el 24 de septiembre de 2014? Quizás no.

Vale la pena destacar el papel del embajador Juan Manuel Gómez Robledo y su papel como el principal empresario de políticas, como se denomina en la documentación y bibliografía al promotor de una política pública. Aunque el embajador Miguel Marín Bosch y la Dra. Patricia Olamendi, ambos como subsecretarios de temas multilaterales, fueron importantes en el proceso de convencimiento de la Sedena y de la Semar, Gómez Robledo, el también subsecretario, tuvo más éxito para el tema de las omp. Gómez Robledo fue subsecretario del área durante el sexenio de Felipe Calderón y logró permanecer en el cargo tras la llegada del gobierno de Enrique Peña Nieto. La continuidad de este funcionario experimentado y promotor de esta agenda entre gobiernos seguramente le permitió relanzar el diálogo entre secretarías con los nuevos titulares de la Sedena y la Semar. Además, es relevante la biografía del embajador Gómez Robledo por dos razones: primera, ha sido un destacado miembro del Servicio Exterior Mexicano en temas multilaterales y jurídicos; y, segunda, en 1994 fue secretario particular 
del titular de Relaciones Exteriores Manuel Tello Macías. ${ }^{33}$ Gómez Robledo es ejemplo claro del cambio de opiniones en el Servicio Exterior Mexicano, incluso en tiempos en que uno de los dos cancilleres Tello dirigiera la SRE. Sólo fue cuestión de tiempo para que la nueva generación de diplomáticos que representa Gómez Robledo llegara a la dirección de la SRE y, con ello, continuara el cambio gradual de la posición de México con respecto a las OMP.

Ahora, la implementación de la decisión abre muchas preguntas que pondrán a prueba lo que Sotomayor llama "consenso convencional" sobre las capacidades que tienen las OMP para cambiar la relación entre civiles y militares, la cercanía entre política exterior y política de defensa nacional y, también, sobre cómo la mejora, o no, de esas relaciones implica una demostración de que se camina hacia la democratización. ${ }^{34}$ Como Sotomayor señala, si no hay un acompañamiento civil en el entrenamiento y despliegue de tropas, México podría vivir el mismo proceso que vivió Brasil al participar en oMP; es decir, no vería cambios sustanciales a favor del control civil sobre el sector militar. En otro tema, es posible, al igual que en el caso de Brasil, que México obtenga relevancia como potencia media multilateral, pero difícilmente podrá mantenerse al paso si no hace mayores cambios. En cuanto a la integración, dependerá del involucramiento posterior del servicio exterior que haya una planeación con la Sedena y la Semar. En Argentina, caso que podríamos estudiar con más detalle, se creó un centro de entrenamiento expresamente diseñado para la educación de las tropas que iban a ser desplegadas en las OMP. México podría aprender de esa experiencia. Finalmente, si se toma en cuenta la experiencia de México en actividades humanitarias de rescate por el plan DN-III, probablemente se adapten en esas tareas, pero no debería restringir esa experiencia previa la posibilidad de que nuestras tropas y mandos militares aprendan de otras áreas del mantenimiento de la paz

${ }^{33}$ United Nations, "Juan Manuel Gomez-Robledo of Mexico Chairman of Sixth Committee: Biographical Note", 13 de septiembre de 2006, http://www.un.org/ press/en/2006/bio3806.doc.htm (enlace consultado el 22 de mayo de 2015).

34 Arturo C. Sotomayor, The Myth of the Democratic Peacekeeper: Civil-Military Relations and the United Nations, Baltimore, Johns Hopkins University Press, 2014, pp. 190-206. 
como las actividades policiales preventivas o sobre disuasión diplomática. La SRE anunció el 13 de marzo de 2015 que México enviaría a dos militares de la Sedena y dos de la Semar a dos misiones de la ONU, MINUSTAH y MINURSo en el Sahara Occidental: un capitán de la Semar y un mayor de infantería de la Sedena se unen al Estado mayor de la minustah; un capitán de la Semar y uno de la Sedena se unen como observadores a la Minurso. ${ }^{35}$ La decisión cumple con la tendencia gradual con la que México decidió integrarse a las OMP, en primer lugar, porque no fue un despliegue de tropas que requiriese la aprobación del Senado; en segundo lugar, porque las actividades de estos militares serán de carácter exploratorio, seguramente para informar de vuelta a ambas secretarías de sus experiencias. Los cuatro militares fueron certificados por la ONU para tareas humanitarias y para la observación de procesos de paz. Valdrá la pena, para la agenda de investigación, conocer de las experiencias de estos militares y ver qué decisiones se toman a futuro, por ejemplo, si se despliega un contingente importante a las dos misiones mencionadas. Finalmente, la decisión de participar en ambas misiones es lógica; en la MINUSTAH, por la posición de México junto al Caribe y la recurrente insistencia de que México colabore en esa misión. Por su parte, la minurso opera en Marruecos, que entre otras cosas fue protectorado español, conque una de sus lenguas oficiales es el español, lo cual podría hacer fluida la participación de los militares mexicanos en dicha misión, ya que, como se reporta en la bibliografía, el idioma que se habla en las misiones es una preocupación usual de los contingentes que llegan a los países con омP.

\section{Conclusiones}

El cambio de política exterior de México en las últimas décadas ha permitido observar diversas dinámicas relacionadas con

${ }^{35}$ Secretaría de Relaciones Exteriores, "México envía los primeros observadores militares y oficiales de Estado Mayor en las Operaciones de Mantenimiento de la Paz de la onu", 13 de marzo de 2015, http://saladeprensa.sre.gob.mx/index. $\mathrm{php} / \mathrm{es} / \mathrm{comunicados} / 5767-138$ (consultado el 22 de mayo de 2015). 
la transición a la democracia y los vínculos entre civiles y militares. La primera es la concentración en el presidente de la relación entre civiles y militares. Las burocracias y cuerpos legislativos en México parecen tener mínimo control sobre las fuerzas armadas para definir política exterior; sólo el convencimiento gradual y circunstancias partidistas favorables cambiaron el escenario de la ausencia de México con efectivos militares en OMP de la ONU. La segunda es la transición democrática ha provocado tensiones burocráticas en la toma de decisión de política exterior que involucren militares: se rompieron durante los años las concordancias entre las burocracias en México, la apertura al exterior en política multilateral ha afectado de manera más contundente al sector diplomático que al militar. La tercera dinámica ha sido un proceso incremental de convencimiento de actores políticos y burocráticos acerca de la importancia de la participación de México en las OMP de la onU. Este proceso incremental ha implicado el convencimiento y cambio de percepciones sobre la doctrina de no intervención en la política exterior mexicana. El caso ayuda a ilustrar cómo una decisión de política exterior implica, además de un cambio incremental y de concordancia burocrática, la necesidad de un contexto y opinión pública favorables para la toma de decisiones. Los elementos domésticos de la política exterior mexicana predominan por encima de las presiones internacionales sobre el tema. Por ello, al menos durante este sexenio, fue posible ver una participación de México en las omp con una opinión pública, contexto político y debates a puerta cerrada de los actores involucrados en condiciones favorables para el presidente y oportunas para el cambio de política exterior. Con ello se da pie a la oportunidad de una mayor apertura de otros actores a fortalecer su relación con las Fuerzas Armadas Mexicanas.

Finalmente, queda una línea de investigación que se debe desarrollar a partir de que los militares mexicanos participen en las OMP: los efectos internos y externos de esta decisión del presidente en la política exterior, la política de defensa nacional e, incluso, temas de derechos humanos y democratización. 


\section{BibliogRAFíA}

Alcalá Ferráes, Luis Gerardo, "Operaciones de Mantenimiento de la Paz", Revista del Centro de Estudios Superiores Navales, 2, abril-junio, 2012, pp. 23-36.

Allison, Graham T., "Conceptual Models and the Cuban Missile Crisis", American Political Science Review, vol. 63, núm. 3, 1969, pp. 689-718.

Benítez, Raúl, "América Latina: operaciones de paz y acciones militares internacionales de las fuerzas armadas", Foro Internacional, vol. 47, núm. 1, 2007, p. 110.

Bland, Douglas L., "A Unified Theory Of Civil-Military Relations", Armed Forces Ė Society, vol. 26, núm. 7, 1999, pp. 7-26.

Camp, Roderic Ai, Las fuerzas armadas en el México democrático, México, Siglo XXI, 2010.

Covarrubias, Ana y Laura Muñoz (eds.), Manuel Tello: por sobre todas las cosas México, México, SRE-IMr, 2007. (Historia Oral de la Diplomacia Mexicana, 3.)

Díez, Jordi, "Legislative Oversight for the Armed Forces in Mexico", Mexican Studies, vol. 24, núm. 1, 2008, pp. 113-145.

Dondisch, Roberto, México en el Consejo de Seguridad de la onU: La historia tras bambalinas, México, sRe/Random House Mondadori/Debate, 2012.

Encinas Valenzuela, Jesús E., "To Do or Not to Do: Mexican Foreign Policy and UN Peacekeeping Operations in the 21st Century", tesis de maestría en Ciencia en Análisis de Defensa, Naval Postgraduate School, Monterrey, California, 2006.

Hill, Christopher, The Changing Politics of Foreign Policy, Nueva York, Palgrave, 2003.

Huntington, Samuel P., The Soldier and the State: The Theory and Politics of Civil-Military Relations, Nueva York, Vintage Books, 1964.

Ibarrola, Javier, El Ejército y el poder: impacto e influencia política en el México moderno, México, Océano, 2003.

James, Patrick y John R. Oneal, "The Influence of Domestic and International Politics of the President's Use of Force", Journal of Conflict Resolution, vol. 35, núm. 2, 1991, pp. 307-332.

Lian, Bradley y John R. Oneal, "Presidents, the Use of Force, and Pu- 
blic Opinion”, Journal of Conflict Resolution, vol. 37, núm. 2, 1993, pp. 277-300.

Lindblom, Charles E., "Still Mudding Not yet Through", Public Administration Review, 39, 1979, pp. 317-339.

Meernik, James, "Presidential Decision Making and the Political Use of Force”, International Studies Quaterly, vol. 38, 1994, pp. 121-138.

Ojeda, Mario, Alcances y límites de la política exterior de México, México, El Colegio de México, 1976.

Pellicer, Olga, "México como potencia media en la política multilateral, 2006-2012”, Foro Internacional, vol. 53, núm. 3, 2013, pp. 873-896.

Rodríguez Ulloa, Carlos, "México ante el multilateralismo del siglo xxi. Entre los principios de política exterior y las Operaciones de Mantenimiento de la Paz", Revista de Relaciones Internacionales de la UNAM, 105, 2009, pp. 109-133.

Schiff, Rebeca L., "Civil-Military Relations Reconsidered: A Theory of Concordance”, Armed Forces Ev Society, vol. 22, núm. 7, 1995, pp. 7-24.

Secretaría de la Defensa Nacional, Programa Sectorial de Defensa Nacional: 2013-2018, México, 2013.

—, Programa Sectorial de Defensa Nacional: 2007-2012, México, 2007.

Secretaría de Marina, Programa Sectorial de Marina, 2007-2012, México, 2007.

, Programa Sectorial de Marina, 2013-2018, México, 2013.

Secretaría de Relaciones Exteriores, "México envía los primeros observadores militares y oficiales de Estado Mayor en las Operaciones de Mantenimiento de la Paz de la onU”, 13 de marzo de 2015, http:// saladeprensa.sre.gob.mx/index.php/es/comunicados/5767-138 (consultado el 22 de mayo de 2015).

Senado de la República, "Discurso del presidente de Francia Nicolás Sarkozy", Diario de los Debates, 11 de marzo de 2009, Segundo Periodo Ordinario, LX Legislatura, Diario 13.

Sepúlveda Amor, Bernardo, "México, el Consejo de Seguridad y el futuro de la onU", Foro Internacional, núm. 142, 1995, pp. 461-475.

-, "Una asignatura pendiente: la participación de México en las operaciones de paz de la onU”, en Miguel Covián (ed.), Cumbre del Milenio: ¿Hacia dónde van las Naciones Unidas?, México, Instituto Matías Romero, Secretaría de Relaciones Exteriores, 2001. 
Serrano, Mónica, "The Armed Branch of the State: Civil-Military Relations in Mexico", Journal of Latin American Studies, vol. 27, núm. 2, 1995, pp. 423-448.

Sotomayor, Arturo C., "México y la onu en tiempos de transición: Entre activismo externo, parálisis interna y crisis internacional”, Foro Internacional, vol. 48, núm. 1, 2008, pp. 238-267.

-, "Why Some States Participate in UN Peace Missions While Others Do Not: An Analysis of Civil-Military Relations and Its Effects on Latin America's Contributions to Peacekeeping Operations", Security Studies, vol. 19, núm. 1, 2010, pp. 160-195.

- The Myth of the Democratic Peacekeeper: Civil-Military Relations and the United Nations, Baltimore, Johns Hopkins University Press, 2014.

United Nations, "Juan Manuel Gomez-Robledo of Mexico Chairman of Sixth Committee: Biographical Note”, 13 de septiembre de 2006, http://www.un.org/press/en/2006/bio3806.doc.htm (enlace consultado el 22 de mayo de 2015).

\section{ENTREVISTAS}

Para esta investigación se realizaron entrevistas con las personas que se indican a continuación. La información general de las entrevistas permitió fundamentar la sección sobre la decisión presidencial. El contenido específico de las entrevistas se reserva en razón de la confidencialidad acordada previamente con los entrevistados. - Mayor y licenciado Armando Tapia, encargado de despacho de la Subdirección de Asuntos Internacionales de la Dirección de General de Derechos Humanos de la Secretaría de la Defensa Nacional. Entrevista realizada el día 29 de abril de 2014 en las instalaciones de la Dirección General de Derechos Humanos de la Sedena en el Distrito Federal.

- Ministro Juan Sandoval Mendiolea, director general para la Organización de las Naciones Unidas de la Secretaría de Relaciones Exteriores. Entrevista realizada el día 4 de abril de 2014 en las instalaciones de la Secretaría de Relaciones Exteriores en el Distrito Federal. 
- Licenciado Sergio Domínguez Bucio, secretario técnico de la Comisión de Relaciones Exteriores, Organismos Internacionales, del Senado de la República. Entrevista realizada el día 21 de abril de 2014 en las instalaciones del Senado de la República en el Distrito Federal. 